\title{
Percutaneous Endoscopic Gastrostomy Site Metastasis in a Patient with Esophageal Cancer
}

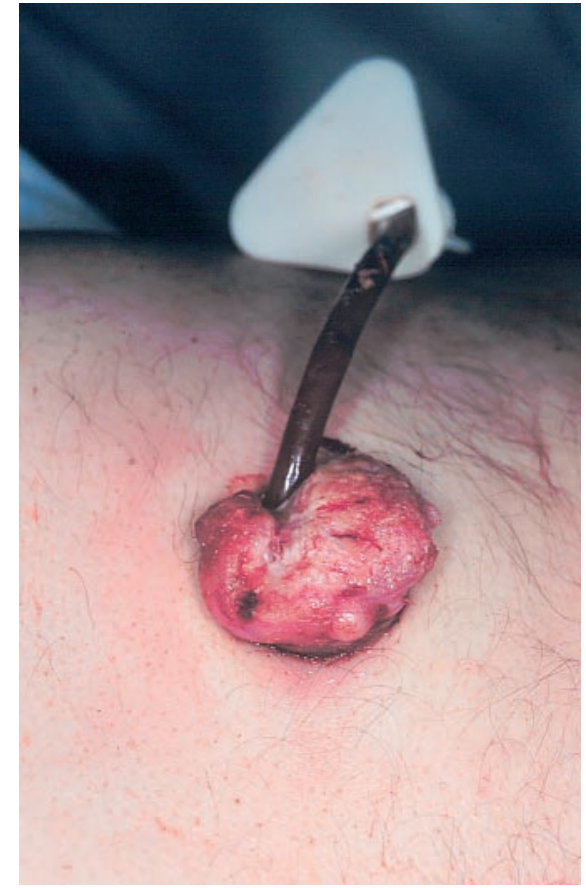

Figure 1 An abdominal wall tumor with a diameter of $3 \mathrm{~cm}$ (Figure 1) had formed at the site of a percutaneous endoscopic gastrostomy (PEG). The PEG had been inserted 10 months earlier using the pull-through technique in a 63-year-old patient with locally advanced squamous-cell carcinoma of the upper esophagus. The primary tumor had been treated with palliative chemoradiotherapy, which resulted in complete remission.

W. Wacke', U. Hecker ${ }^{1}$, C. Woenckhaus ${ }^{2}$, M. M. Lerch ${ }^{1}$

${ }^{1}$ Division of Gastroenterology and Endocrinology, Ernst Moritz Arndt University, Greifswald, Germany ${ }^{2}$ Institute of Pathology, Ernst Moritz Arndt University, Greifswald, Germany

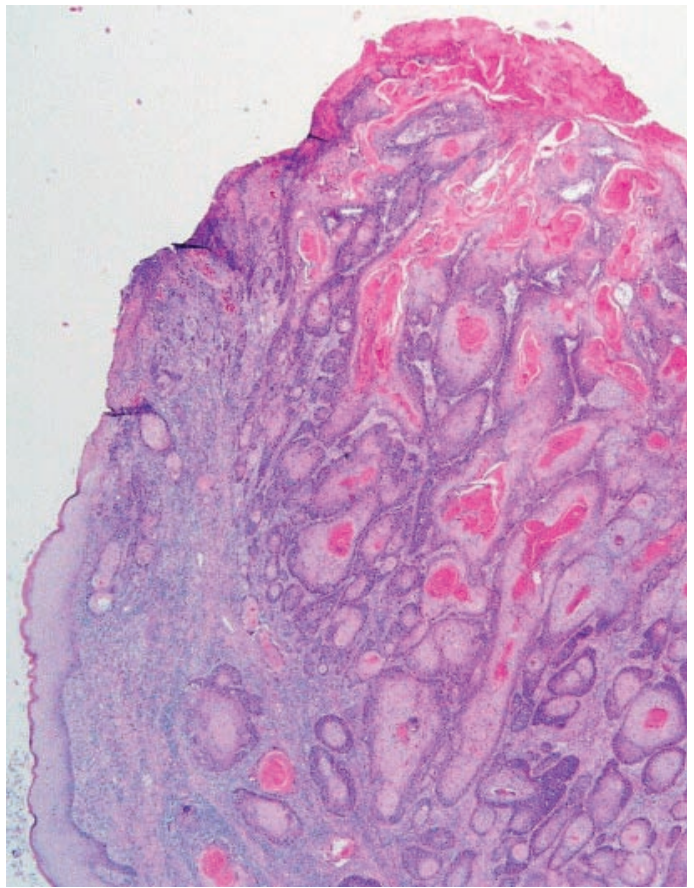

Figure 2 The PEG-associated tumor was histologically identical to the original malignancy (Figure 2, hematoxylin/eosin stain) and was treated by resection of the affected abdominal wall and subtotal gastrectomy. This case illustrates the fact that malignant cells from a stenotic esophageal cancer can be sheared off when a PEG plate is being pulled through and that they remain capable of forming metastases even after chemoradiotherapy.

Corresponding Author

W. Wacke, M.D.

Division of Gastroenterology

and Endocrinology

Ernst-Moritz-Arndt-Universität

Greifswald

Friedrich-Loeffler-Straße 23a

17487 Greifswald

Germany

Fax: +49-3834-866605

E-mail: wacke@uni-greifswald.de 